\title{
The Skatepark Mathematics Extravaganza
}

\author{
William H. Robertson \\ The University of Texas at El Paso, El Paso, USA
}

\begin{abstract}
In the fall of 2014, a series of live demonstrations and field-based activities were lead by a team of educators and top action sports athletes who performed at local high schools. These events, entitled the "Skatepark Mathematics Extravaganza", were done in order to engage high school students in focused explorations of mathematics set in a real world setting that is relevant to youth culture, namely, skateboarding and bicycle motocross (BMX). These activities incorporated mathematics for the students to do after the demonstration in meetings with classes in which the Action Science Stunt Team performed maneuvers on ramps at the high school and from which students collected real world data. These demonstrations and subsequent field-based activities allowed the students to explore practical applications of mathematics principles in geometry and algebra in the context of BMX and skateboarding. Approximately 4,000 students in the 10th grade participated in the six on-campus events.
\end{abstract}

Keywords: action science, mathematics, geometry, algebra, science, physics, skateboarding, bicycle motocross (BMX)

\section{Introduction}

“Learn. Unlearn. Relearn”. (Davidson, 2001)

How can you get young people interested in science and mathematics? What efforts are there to integrate the experiences of students into the things they need to do and learn in school? How can action sports, like skateboarding and bicycle motocross (BMX), be used to teach physics, algebra, and data collection, and help students grow in their engagement and motivation in science, technology, engineering, and mathematics (STEM)? The answer lies in part with the use of action science within a Skatepark Mathematics Extravaganza!

During the week of November 17-21, 2014, a series of live demonstrations and field-based activities were led by a team of educators and professional BMX riders and skateboarders who performed at six high schools in the El Paso, Texas. These events, entitled the "Skatepark Mathematics Extravaganza", were done in order to engage local students in focused explorations of mathematics set in a real world setting that is relevant to youth culture. Following each demonstration, students participated in field-based data collection activities designed to give an academic purpose to the presentation. This combination of entertainment with an educational emphasis is often termed "edutainment".

For education to be transformative, the traditional relationship between the teacher and the student, wherein the teacher delivers content while students listen passively, is rejected. Instead, teachers serve as facilitators, co-learners mentors, and role models. Teachers need to present themselves as respectful guides and compassionate helpers who grant students the opportunities to become actively involved in classroom

William H. Robertson, Ph.D., associate professor, Teacher Education Department, College of Education, The University of Texas at El Paso. 
interactions and in their own learning (Hasslen, 2008). More importantly, educators become change agents by working to establish links within their communities, and trying to engage their students in active learning projects that require them to interact with individuals outside the school (Donovan, 2002). For the transformative teacher, learning can take place in different venues and not solely in the classroom (Palmer, 1998).

The Skatepark Mathematics Extravaganza was designed to teach fundamental mathematics concepts in algebra and geometry in an approach that utilized transformative educational strategies, which helped students move from memorizing facts and content to constructing knowledge in meaningful and useful manners. After each demonstration, the team-led activities incorporated mathematics for the students to do, in which the athletes performed maneuvers on ramps at the schools and the students collected real world data. These demonstrations and subsequent field-based activities allowed the students to explore practical applications of mathematics principles in geometry and algebra in the context of BMX and skateboarding. In this effort, the team entertained over 4,000 at the six participating high schools, and did a total of 16 sessions of the skatepark mathematics activities for an estimate of 1,750 students as well. By all accounts, these events were successful based on the feedback from students, faculty, and the administration. The Action Science Stunt Team also made the local news on Channels 4, 7, 9, and 14, as well as seeing tremendous social media traffic on Facebook, Twitter, and Instagram.

\section{Teacher Preparation}

Prior to each event on the six campuses, professional development sessions were offered for the participating mathematics faculty. In the course of an on-site workshop session, the 30 mathematics teachers who took part in the training received instruction in the unique approach present in the Skatepark Mathematics Extravaganza and their role in this effort before, during, and after the event.

The identified teachers participated in a 90-minute workshop on site at each school in order to familiarize themselves with the concepts and activities, which were aligned to the mathematics being studied in their classrooms. The activities associated with the Skatepark Mathematics Extravaganza addressed both the objectives and enduring knowledge of content and process skills for specific Texas Essential Knowledge and Skills (TEKS) standards.

In the days leading up to the on-campus activities, the teachers were to utilize materials in their classrooms prior to each event that would get students engaged in the mathematics to be presented, and also to inform students through the use of compelling video materials of the unique and creative learning experience in which they would be immersed at their schools.

Before each event, teachers were instructed to share resources from the Dr. Skateboard's Website and YouTube channel (see Appendix) with the students as well as to organize their classes into teams for the skatepark field-based data collection exercises. Additionally, they were to make copies as needed of the field-based data collection tool for each event, so that each team within the class had a copy and a designated recorder. In each class, teachers were to discuss the mathematical topics and challenge the students to seek connections to the Skatepark Mathematics Extravaganza event on the campus and the material they were covering in class.

Teachers were also instructed in the procedures for the activities that would take place on the day of the on-campus event, which included a live demonstration by the Action Science Stunt Team, consisting of 
professional and top amateur athletes in skateboarding and BMX, lead and coordinated by Dr. Bill Robertson, a university science educator at the University of Texas at El Paso and a professional skateboarder in his own right.

\section{On-site Demonstrations}

During the week of November 17-21, 2014, a series of live BMX and skateboarding demonstrations were done at six local high schools involved in a college readiness program run in conjunction with the local university. The Skatepark Mathematics Extravaganza was designed to engage local students in explorations of mathematics in a real world and youth-centered context.

The Action Science Stunt Team, a group of professional athletes specializing in the areas of skateboarding and BMX, were utilized in order to demonstrate the mathematical concepts found in their routines. This group, with their extensive experience delivering performances in educational settings, provided the motivational engagement experience that served to motivate the students as well as impress them with their incredible feats. These athletes performed their high-flying maneuvers that formed the centerpiece of the Skatepark Mathematics Extravaganza and also served as the direct link to the mathematical content the students encountered in their high school classes. Without these athletes, the action would not have been authentic, and this approach provided a new and informal pathway that invited students to learn, in that they may not be readily attracted to mathematics, but did recognize and respect the difficulty of the maneuvers performed in the demonstration.

Each live demonstration at the six high schools was presented in order to increase motivation and participation through a unique setting. This approach showed that action sports could be used as teaching and learning vehicles for students, teachers, and the community in the subject of mathematics, specifically in the areas of geometry and algebra. The presentations also introduced students to concepts in physics, such as center of gravity, acceleration, motion, and velocity, which were then explored in greater depth mathematically in the field-based data collection activities.

Each demonstration was done in tandem with students performing a series of activities at each high school that emphasized the defined mathematics concepts of BMX and skateboarding. In order to create student interest and promote new connections to the understanding of fundamental physics concepts, there is a need for new approaches and methods that are both contemporary and relevant. The provided activities incorporated mathematics for the students to do after the demonstration, in which the team performed maneuvers on ramps at the high school and students collected real world data.

The focus of this effort was an approach defined as action science, a curriculum approach that integrates of live action, student-centered pedagogical strategies, video instruction, and classroom activities. The use of familiar activities, situations, and objects, such as skateboarding and BMX, around which students can explore and explain scientific concepts can be defined as action science. The Skatepark Mathematics Extravaganza was an extension of the action science approach designed in order to bring relevance to mathematics education.

\section{Field-based Data Collection and Classroom Activities}

The field-based data collection activities provided the participating students with an opportunity to make calculations and defend answers to the group. Each activity included a series of open-ended questions, which required them to actively interact with the content of the explorations. This required the student teams to 
negotiate the connections to the content not only individually, but also as a group, which in turn, engaged students in the exploration of mathematics content in unprepared and unpredicted manners. As one participating student commented, "We might be doing all the tricks they are doing, but we are doing everything behind the scenes, all the mathematical equations that they are performing".

As students explored content in active and relevant ways, they developed a broader understanding of the concepts in application. When they collaboratively related what they were learning, seeing, or doing, they can began to see similarities in their understandings, as well as self-identify misconceptions they may have had about content material (Bybee et al., 2006). This sharing within cooperative groups is a fundamental strategy in constructivism as it allows the teacher to facilitate the learning process, and also helps to develop a common base of experiences on which to help students make connections to the content. Hands-on explorations of simple topics that utilize problem-solving strategies combined with collaborative interactions among students, help to build an understanding of processes and concepts (Apple, 1993).

The task of the students was to gather data from three different stations in the skatepark where the riders would perform maneuvers. The first station was the half-pipe, a semicircular ramp structure, where riders moved back and forth and where students had to calculate angular motion. The second station was an inclined plane that was approximately one meter tall and three meters long. The riders would drop in on the inclined plane ramp and the students would record the time it took the rider to reach the edge of the ramp. From the data, the students could calculate the acceleration of each rider. The third station was a grind rail, a metal beam affixed to elevated supports on which a rider would travel up to and slide across. The students had to calculate the velocity of the rider as each athlete got to the grind rail, and then determine at the final velocity a rider achieved at the end.

Each station was marked with a sign, and a team of athletes acted as the peer leaders for learning with the students, so that the athletes from the demonstration were the guides in the data collection exercises. Each participating class began at a specific station and students collected data at each of the three stations within a 45-minute class period. These hands-on active learning experiences allowed the students work in collaborative teams of about five members with guidance from the teachers and the athletes. The students were thus provided with a common base of experiences in a field-based research approach. The teams gathered data from the three different stations in the skatepark where the riders had just performed their high-flying maneuvers, and as such, the students engaged in self-directed and meaningful learning.

Following the data collection exercises, the teams returned to their classrooms, where the participating teachers could follow up with provided classroom activities that built on the concepts in algebra and geometry found in the demonstrations and field-based activities. With a data collection worksheet for each participating team, teachers reported that they used the exercise in order to pool data across all classes, and thereby look for trends that involved analysis and synthesis of data, characteristics of critical thinking. As one participating teacher commented, "They are having a good time. They are involved in taking down the data that they are collecting. They are going to be more interested in that data when we are working on it in the classroom".

The classroom activities provided the participating students with an instructional series rich with mathematics content information. The material, available in the form of an activity booklet, included topics such as foundations of functions in Algebra II and the use of geometric thinking and reasoning in geometry. This allowed the students in the classroom to focus on mathematics topics set in the context of something students enjoy doing, such as skateboarding and BMX, while engaging students in the exploration of 
mathematics in a real world context.

These efforts, from the engagement of the live demonstration, through the exploration and explanations found in the field-based data collection activities to the elaboration of the classroom activities allowed multiple opportunities for both formative and reflective evaluation. This approach provided students with opportunity to gauge their own progress on the concepts in mathematics. It also provided the participating classroom teachers with evidence of what students learned as a result of the experiences with skatepark mathematics. Finally, the entire experience was designed with a $5 \mathrm{E}$ constructivist approach (Engagement, Exploration, Explanation, Elaboration, and Evaluation) as an organizing framework for the teachers and students

\section{Conclusion}

The connection of mathematics content to real world experiences is vital in order to engage students effectively and to provide them with a reason to delve into deeper conceptual understandings. In terms of the Skatepark Mathematics Extravaganza, the use of skateboarding and BMX shows how popular activities that resonate with students can help to make learning mathematics topics fun and enjoyable.

The Skatepark Mathematics Extravaganza integrated a relevant and practical setting for learning centered on youth culture that allowed for the study of fundamental mathematics principles to be brought forward in skateboarding and BMX. For the teacher, there were also activities to integrate in the classroom, videos that can be accessed via the Internet, as well as a lot of great ideas for ways to engage and to facilitate active learning in the classroom.

Edutainment has recently been a major growing area of education, showing great promise to motivate students with relevant activities. The Skatepark Mathematics Extravaganza on-site demonstrations and field-based activities are examples of cutting-edge fusions of popular action sports demonstrations and mathematics concepts designed to engage and to motivate high school students.

The importance of using relevant and practical methods of instruction and curriculum delivery that build on student interests and increase enjoyment in the learning process are critical at the high school level, especially in the fields of algebra and geometry. The use of edutainment in this manner is meant to inspire broader interest in mathematics for high school students and to develop a culture of education that makes learning more accessible to all students.

\section{References}

Apple, M. W. (1993). Official knowledge. New York, N.Y.: Routledge.

Bybee, R. W., Taylor, J. A., Gardner, A., Van Scotter, P., Powell, J. C., Westbrook, A., \& Landes, N. (2006). The BSCS 5E instructional model: Origins, effectiveness, and applications (Executive Summary). Retrieved September 9, 2007, from http://www.bscs.org/pdf/bscs5eexecsummary.pdf

Davidson, C. N. (2001). Now you see it: How the brain science of attention will transform the way we live, work and learn. New York, N.Y.: Viking Penguin.

Donovan, B. (2002). An illustration of practice in search of theory. Theory and Practice, 41, 17-26.

Hasslen, R. (2008). From a tarpaper shack to a transformed classroom: A teacher's journey. Kappa Delta Pi Record, $44,52-54$.

Palmer, P. J. (1998). The courage to teach: Exploring the inner landscape of a teacher's life. San Francisco, C.A.: Jossey-Bass. 
Appendix: Professional Development Resources (Websites)

1. Overview of Skatepark Mathematics: https://www.youtube.com/watch?v=UeN73_OJ61o;

2. Masters of physics documentary: https://www.youtube.com/watch? $\mathrm{v}=03 \mathrm{tYF} 4 \mathrm{sFY} 98$;

3. The history of action science: https://www.youtube.com/watch?v=HC9oBH04qWY;

4. Action science video with mathematics - Newton's second law of motion: https://www.youtube.com $/$ watch? $v=x y 3 x$ LTeWgpg;

5. Dr. Skateboard's Website: http://www.drskateboard.com/;

6. Dr. Skateboard's YouTube channel: https://www.youtube.com/user/drsk8board. 